\title{
Minithoracoscopy for pleural effusions
}

\author{
RA Malthaner MD FRCSC FCCP, RI Inculet MD FRCSC FACS FCCP \\ Division of Thoracic Surgery, Department of Surgery, \\ The University of Western Ontario, London Health Sciences Centre, London, Ontario
}

\section{RA Malthaner, RI Inculet. Minithoracoscopy for pleural effusions. Can Respir J 1998;5(4):253-254.}

The current management of pleural disease often requires direct visualization and biopsy of the pleural space using thoracoscopy. A diagnostic and therapeutic approach to pleural disease is described that uses a new $2 \mathrm{~mm}$ rigid thorascope. The technique allows complete visualization, biopsy and drainage of the pleural space with rapid recovery and minimal pain.

Key Words: Minimally invasive surgery, Pleural effusions, Pleuroscopy, Thoracoscopy

\section{Minithoracoscopie dans les cas d'épanchement pleural}

RÉSUMÉ : Le traitement actuel des affections pleurales exige souvent la visualisation directe et une biopsie de la cavité pleurale à l'aide d'un thoracoscope. Dans le présent article, il est question d'une intervention diagnostique et thérapeutique qui se pratique au moyen d'un nouveau thoracoscope rigide de $2 \mathrm{~mm}$. La technique décrite non seulement permet une visualisation complète, une biopsie et le drainage de la cavité pleurale, mais s'accompagne d'une récupération rapide et de très peu de douleurs.
$\mathrm{T}$ horacoscopy is used regularly in the diagnosis and management of pleural disease. The pleural space can be visualized by using a variety of instruments, including a rigid pleuroscope, a flexible bronchoscope and a specially designed thoracoscope coupled to a microcamera system. Current rigid instruments have a large calibre and often result in painful incisions, especially when the intercostal space is narrow. We describe our approach to investigating and treating pleural effusions using a new $2 \mathrm{~mm}$ thoracoscope (MiniSite $2 \mathrm{~mm} 0^{\circ}$ Laparoscope, Auto Suture Company).

\section{TECHNIQUE}

The procedure is carried out under general anesthesia with single-lung ventilation using a double-lumen endotracheal intubation. The patient is placed in the lateral thoracotomy position. The pleural space is entered via a $3 \mathrm{~mm}$ incision using a curved hemostat (Figure 1). A small trocar (MiniSite Introducer, Auto Suture Company) is used as a trocar for the $2 \mathrm{~mm}$ miniscope. The scope is then inserted through the trocar to allow direct visualization of the pleural space. The scope may be attached to a standard video camera for full on-screen visualization if desired. Pleural fluid is aspirated using the side tubing or via a second $3 \mathrm{~mm}$ hole through another mini-introducer. Pleural or tumour biopsies are taken under direct vision through the second MiniSite Introducer. Pleurodesis, if desired, can be achieved using $5 \mathrm{~g}$ of sterile talc mixed in $100 \mathrm{~mL}$ saline as a slurry through either the second trocar or via the side tubing of the camera port. A 20 French chest tube is inserted through the camera port and is placed to $20 \mathrm{~cm}$ underwater suction. 


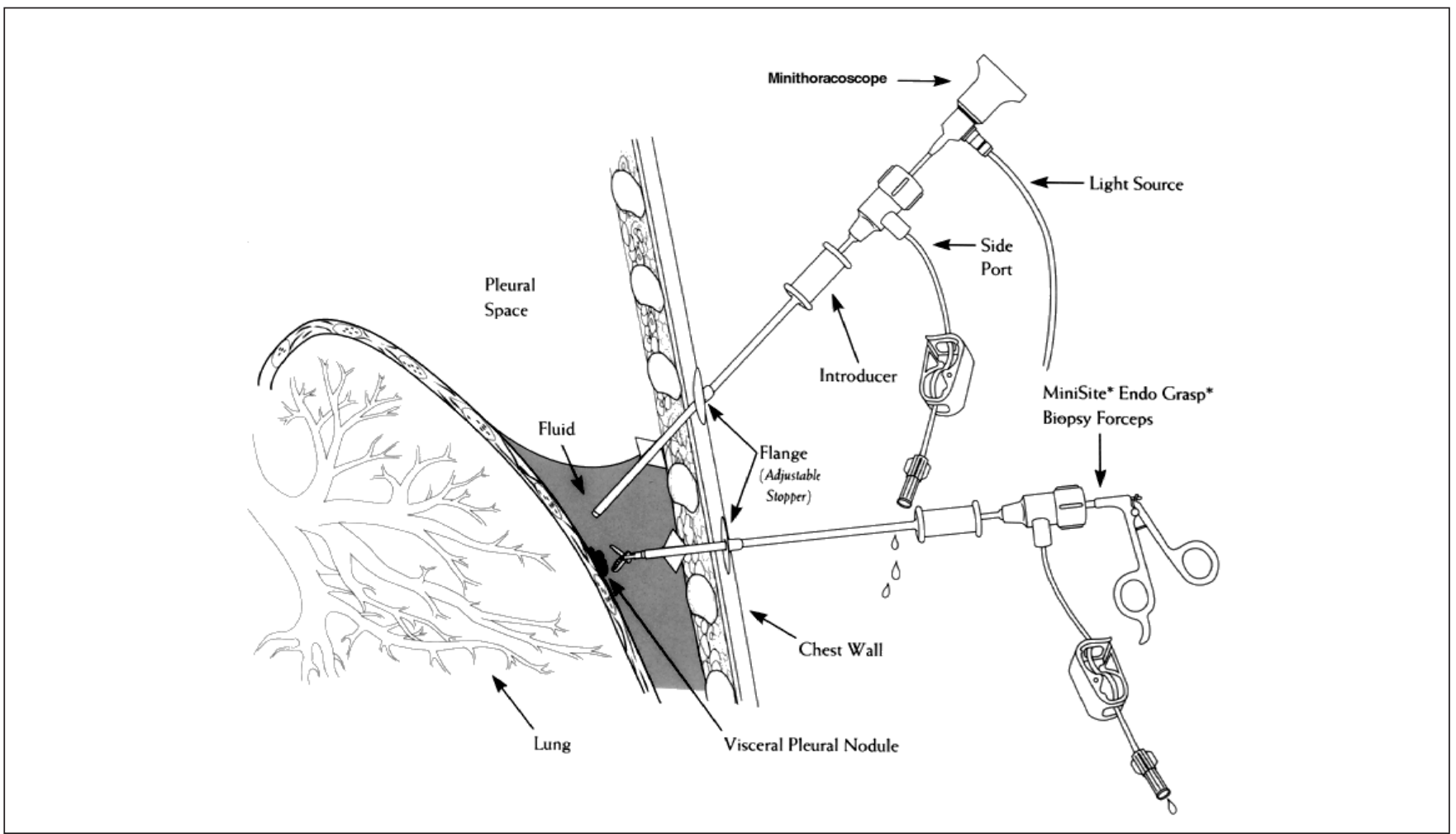

Figure 1) Minithoracoscopy for pleural effusions

\section{RESULTS}

This technique was performed on three patients with uncomplicated pleural effusions. The visualization of the pleural space was excellent, and biopsies were completed in two of the three patients. One patient had a traumatic serous effusion that was drained. The second patient had a malignant effusion secondary to a breast carcinoma that was successfully pleurodesed. In the third patient, the miniscope was used to confirm the presence of an entrapped lung and a loculated effusion secondary to a mesothelioma. All procedures were either diagnostic or therapeutic. Patients' postoperative pain was minimal.
The lengths of hospital stay were two, three and five days, respectively.

\section{DISCUSSION}

Minithoracoscopy with the $2 \mathrm{~mm}$ thoracoscope provides an alternative to standard pleuroscopy for the diagnosis and therapy of pleural disease. The scope is, however, a delicate instrument that can easily be damaged if used with excess vigour. It retains all of the advantages of standard video-assisted technique with the added benefit of less pain and a smaller incision. Preliminary experience supports this technique as less painful and equally effective as standard methods. 


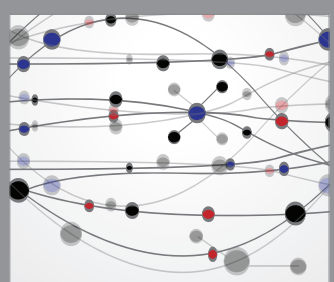

The Scientific World Journal
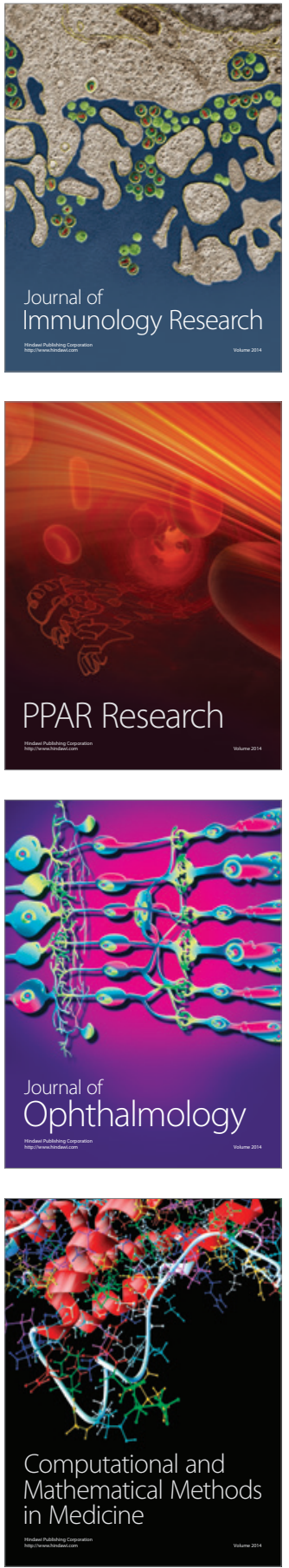

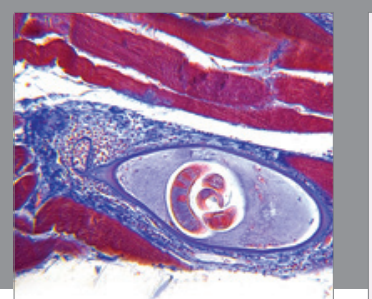

Gastroenterology Research and Practice

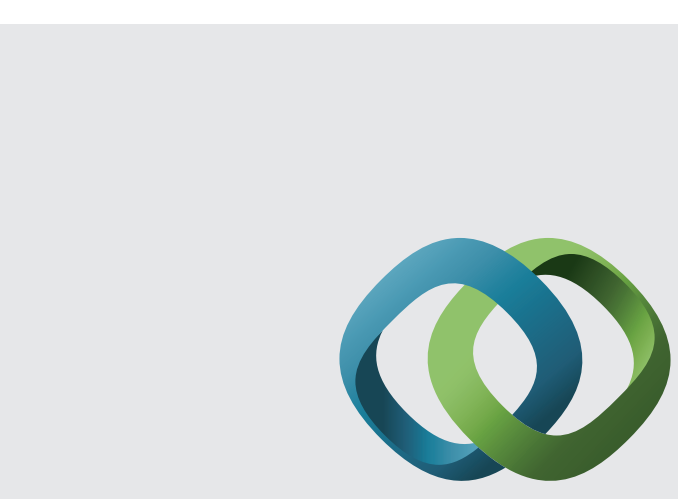

\section{Hindawi}

Submit your manuscripts at

http://www.hindawi.com
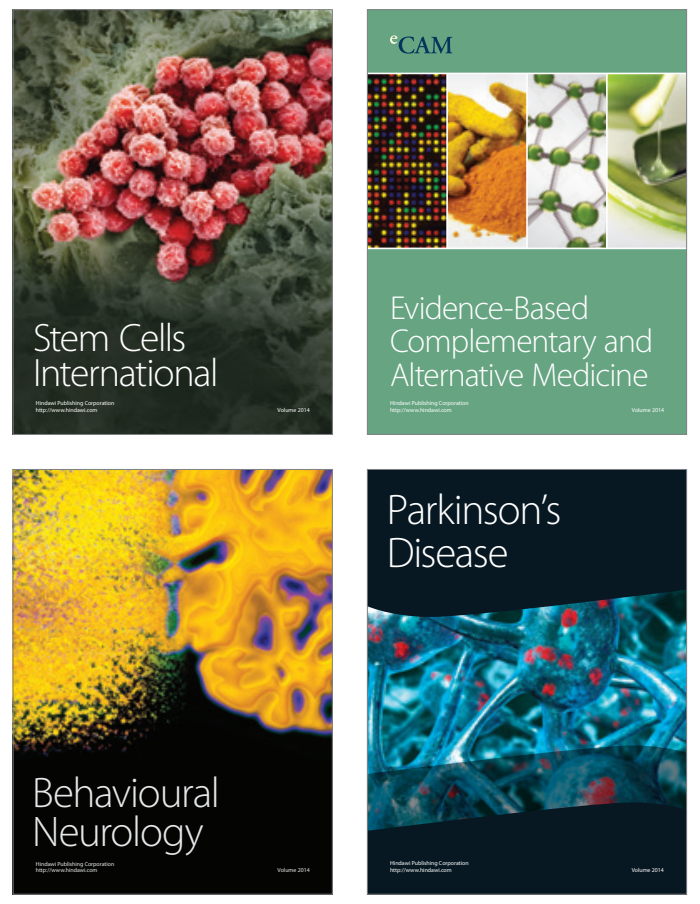
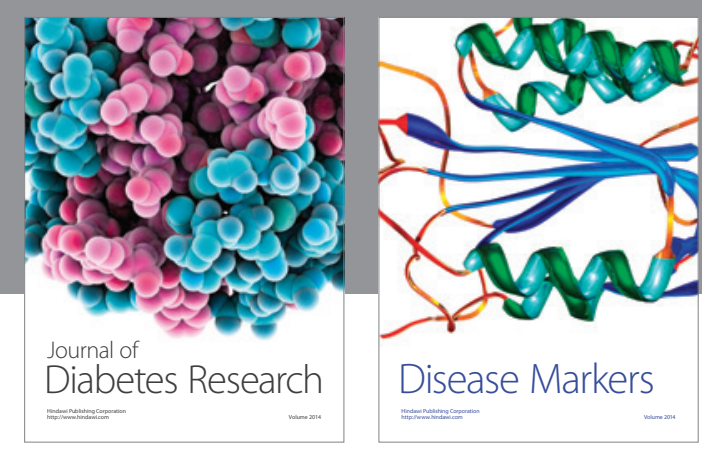

Disease Markers
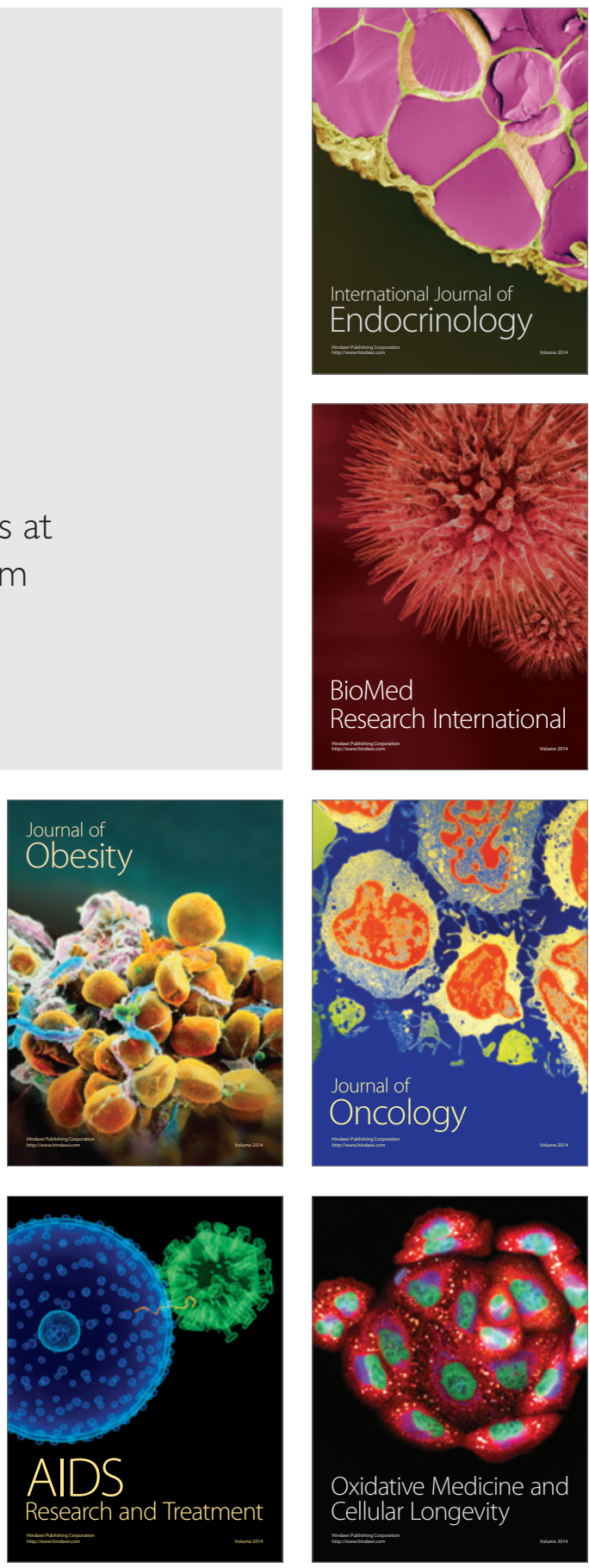